\title{
THE SITE OF ACTION OF INNOVAR IN THE BRAIN
}

\author{
Hisashi Yanagida, M.D. ${ }^{*}$ and Hideo Yamamura, M.D. $\dagger$
}

DROPERIDOL ${ }^{1}$ AND FENTANYL ${ }^{2}$ usually in a combination of $50: 1$ known as Innovar have been described as safe and useful members of the anaesthetic armamentarium. Innovar has been used to produce a state referred to as neurolept analgesia, characterized by a reduced awareness of both oneself and of the environment, by analgesia and by a laissez faire attitude to treatment ${ }^{3}$ without however producing unconsciousness. Clinical and pharmacological observations of the action of Innovar have been reported by many authors. ${ }^{4-6}$ However little information is available with respect to the site of action of Innovar in the brain. The state of unawareness produced by Innovar is known to have a functional relationship to the brain stem reticular formation ${ }^{7}$ the hypothalmus, ${ }^{8}$ and the pontine reticular formation. ${ }^{9}$ Also pain sensation is known to be related to specific and non-specific thalamic nuclei.

The present investigation was done to ascertain what changes might be induced in the electroencephalogram (EEG) and in the behaviour of chronic cat preparations by Innovar injected locally into the mesencephalic reticular formation, the posterior hypothalamus, the centro-median and the ventropostero-lateral thalamic nuclei.

\section{Methods}

Experiments were carried out on six adult cats weighing from 3.5 to $4.0 \mathrm{~kg}$. The technique of stereotaxic placement and utilization of subcortical recording cannulae has been described elsewhere. ${ }^{10-12}$ In our cats, EEG recording electrodes and stainless steel cannulae (about $1 \mathrm{~mm}$ in diameter) were implanted chronically at several sites in the brain. EEGs were recorded from the left surface of the dura mater and the left hippocampus dorsalis by bipolar leads. The sites injected were: the left mesencephalic reticular formation, the left posterior hypothalamus, the left pontine reticular formation, the centromedian thalamic nucleus, and the ventropostero-lateral thalamic nucleus. The cannulae were fixed to the skull with dental cement. The animals were placed in an observation box with a one-way viewing window. They were connected to a Nihon-Koden electroencephalograph via a skull plug and connecting wires. The animals were fully mobile within the observation box. Pin-prick stimuli were applied intermittently.

One $\mathrm{ml}$ of Innovar was dissolved in $10 \mathrm{ml}$ of saline. The resulting solution has a $\mathrm{pH}$ of 7.0 and $0.005 \mathrm{mosm} /$ microlitre. Before the experiment proper was started, it had been confirmed that the solvent of the Innovar, adjusted for $\mathrm{pH}$ and osmolarity,

\footnotetext{
"Assistant, Department of Anesthesiology, School of Medicine, University of Tokyo, Japan.

†Professor and Chairman, Department of Anesthesiology, School of Medicine, University of Tokyo, Japan.

\$The Innovar referred to in this study consists of fentanyl $0.02 \mathrm{mgms}$, and droperidol 1.0 $\mathrm{mgm} / \mathrm{ml}$, while Innovar, commercially available in North America contains fentanyl $0.05 \mathrm{mgms}$. and droperidol $2.5 \mathrm{mgms}$. 
injected into any part of the brain, exerted no effect either on the EEG or on the animal's behaviour. The local injection of 20 microlitres of Innovar was done over a period of ten seconds. The accuracy of electrode placement into the subcortical sites was confirmed by subsequent histological examination. The state of awareness is characterized by the pattern of activity in the electrocardiographic recordings obtained from the cerebral cortex of man and experimental animals. The activity consists of fast, low amplitude waves while sleep, on the other hand, shows an EEG pattern of deactivation which is characterized by high amplitude and slow wave activity. ${ }^{7}$ Also, the regular slow waves of the hippocampus appear during arousal. ${ }^{13}$ On the other hand, the disappearance of hippocampus slow activity appears in the sleep state with the exception of paradoxical sleep. ${ }^{14}$ Therefore, we shall refer to activated or deactivated patterns in the neocortical and hippocampal electroencephalogram.

\section{Results}

Figure $1(\mathrm{~B})$ shows the results obtained from a representative animal which had 20 microlitres of Innovar injected into the left mesencephalic reticular formation. Before the injection, the electroencephalogram had shown low voltage, fast activity in the neocortex and regular slow activity in the hippocampus (Figure 1(A)). At the same time the cat was behaviourally awake. Approximately 3 minutes after the injection, activation in the hippocampal recording was quite evident and more marked than that which had been observed as spontaneous activity prior to the injection. The electroencephalogram from the neocortex was not influenced by the injection of Innovar into the mesencephalic reticular formation (Figure 1(B)). The animals were responsive but it was observed that the response to pin-prick was absent.

Figure 1(c) shows one of the representative patterns obtained with the injection of a dose of 20 microlitres of Innovar into the left posterior hypothalmus. A deactivated electroencephalographic pattern was recorded from the neocortex and a hippocampal seizure pattern was observed (Figure 1(c)). The animals became unresponsive and failed to respond to pin-prick stimuli. The electroencephalographic and behavioural changes appeared approximately 3 minutes after the injection and lasted for approximately 100 minutes. After 160 minutes spontaneous activation of the neocortical and hippocampal electroencephalogram returned and the animals awoke.

Some 3 minutes after the administration of Innovar into the pontine reticular formation the same results were obtained as with the injection into the mesencephalic reticular formation. The changes lasted for approximately 40 minutes and some 60 minutes after the injection the electroencephalogram returned to its preinjection configuration.

Figure 2 shows the results obtained from one of the representative cases injected with a dose of 20 microlitres of Innovar into the centro-median thalamic nucleus. Some 3 minutes after the injection a deactivated pattern was observed on the EEG from the neocortex, while the hippocampal activated pattern was not influenced. The animal became behaviourally quiet and no response to pin-prick stimulation 
A

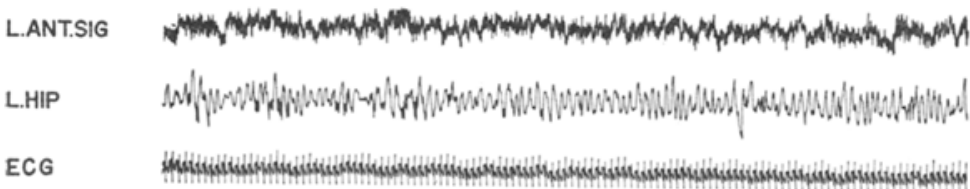

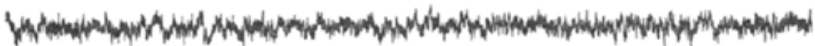

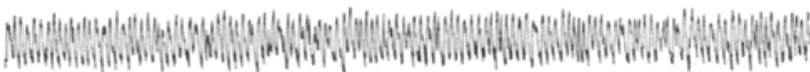

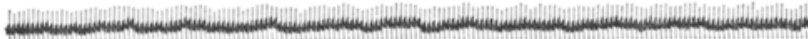

$c$

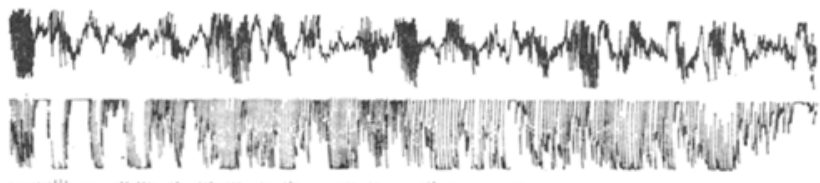

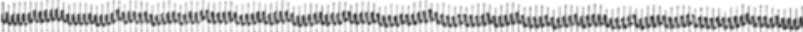

D

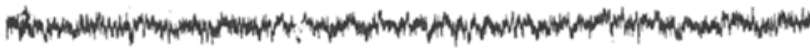

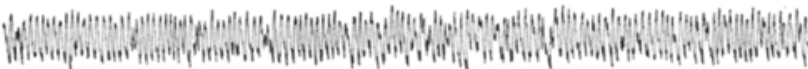

(1,

Figure 1.

L. ANT. SIG.: left anterior sigmoid gyrus

L. HIP: left hippocampus dorsalis

ECG: electrocardiogram

A: control state

B: approximately 10 minutes after injection into the mesencephalic reticular formation. The electrocardiogram of the hippocampus now is more regular than the control state. No behavioural changes were observed and response to pinprick stimulation remained normal.

c: approximately 10 minutes after injection into the posterior hypothalamus. Note the deactivated pattem in the anterior sigmoid gyrus and seizure pattern in the hippocampus. The animal, at this point, was unresponsive to pin-prick stimulation.

D: approximately 10 minutes after injection into the pontine reticular formation. The hippocampal electroencephalogram is more regular than in the control state. No behavioural changes were observed and response to pin-prick stimulation remained normal. 

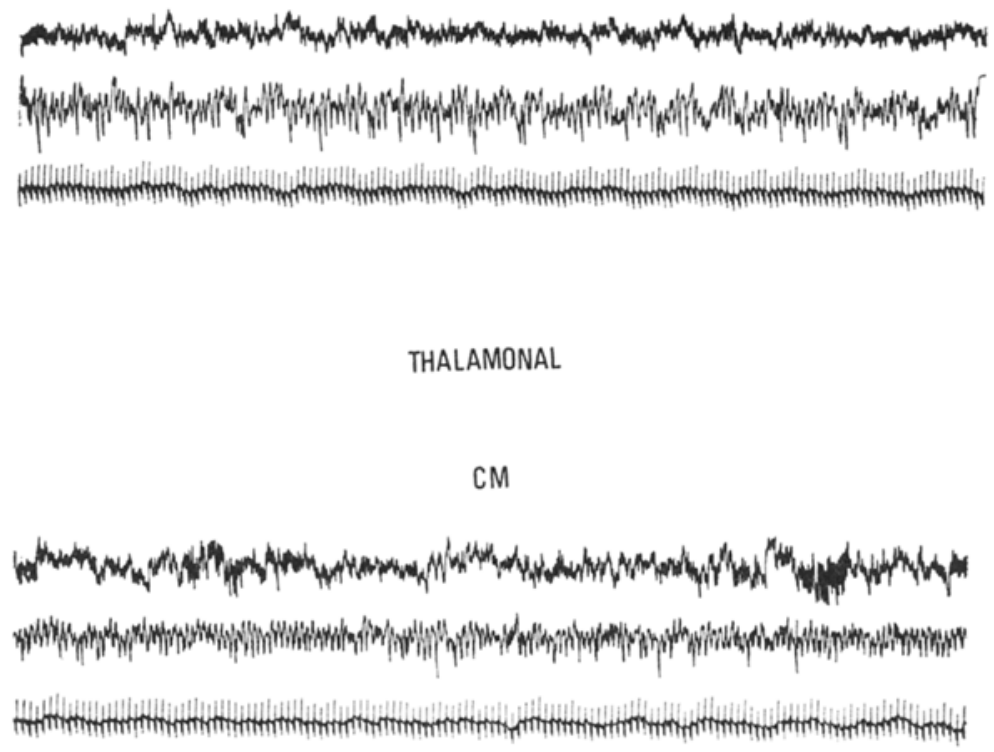

VPL

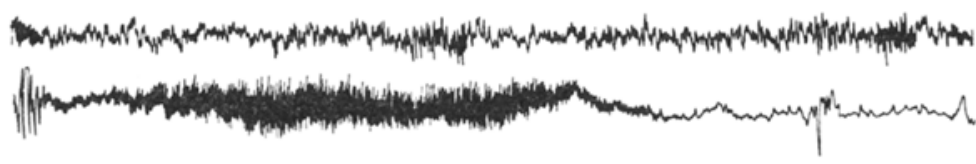

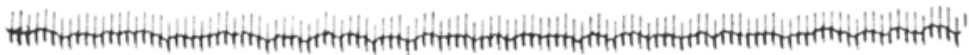

ISEC

Figure 2.

CM: centro-median thalamic nucleus.

VPL: ventropostero-lateral thalamic nucleus.

Approximately 15 minutes after injection into the centro-median thalamic nucleus a deactivated pattern in the anterior sigmoid gyrus and regular slow wave in the hippocampus were observed. Approximately 17 minutes after the injection a seizure pattern was observed in the hippocampus and the animal became unresponsive to pin-prick stimulation.

was observed. All these changes lasted for approximately 40 minutes, whereupon both the EEG and the animal's behaviour returned to the pre-injection state.

When 20 microlitres of Innovar were injected into the left ventropostero-lateral thalamic nucleus, again a deactivated pattern was observed in the neocortex, while hippocampal seizure patterns were quite evident. The animal became quiet and there was no response to pin-prick stimulation. These changes lasted for $110 \mathrm{~min}$ utes and then returned to normal. 


\section{Discussion}

That the electroencephalographic and behavioural changes observed during these experiments were due to the local application of Innovar into the various regions is supported by the following observations: $(a)$ electroencephalographic and behavioural changes were not observed after the administration of an identical volume of the solvent of Innovar adjusted for $\mathrm{pH}$ and osmolarity using the same speed for the injection; $(b)$ no changes in the EEG and in behaviour seemed to be attributable to mechanical stimulation caused by the administration of the solvent of Innovar; $(c)$ no electroencephalographic or behavioural changes were observed following the intravenous administration of 20 microlitres of Innovar; $(d)$ Innovar injected locally into regions such as those injected in these experiments have been shown to diffuse within a radius of $1 \mathrm{~mm} .{ }^{15}$

While many problems associated with the experimental design still are not resolved, other investigators too have used the method of direct injection into the brain. ${ }^{16}$ We have made the assumption that the electroencephalograph and behavioural changes after the administration of 20 microlitres of Innovar may be due to the pharmacological effect of Innovar.

When Innovar was injected into the brain in doses exceeding 40 microlitres, the animal vomited. On the other hand, no electroencephalographic nor behavioural changes were observed after the injection of less than 10 microlitres of Innovar into the brain.

The state of analgesia and laissez faire after the administration of Innovar may be explained as follows: $(a)$ there occurs a dissociation between neocortical and hippocampal activity after the administration of Innovar into the posterior hypothalamus; $(b)$ the neocortical deactivation was induced by the administration into the centro-median thalamic nucleus; $(c)$ neocortical deactivation was induced after the administration of Innovar into the ventropostero-lateral thalamic nucleus. Hippocampal deactivation patterns were never observed following the application of Innovar into the above sites.

It would appear from these results, that the posterior hypothalamus, the centromedian and the ventropostero-lateral thalamic nuclei are more sensitive to the action of locally applied Innovar than are the mesencephalic reticular and pontine reticular formations which have been examined in this study. The state of analgesia and laissez faire were not observed by the administration of Innovar into these two reticular formations. No ready interpretation is available for the appearance of hippocampal seizure patterns after the administration of Innovar into the posterior hypothalamus or the ventropostero-lateral thalamic nucleus.

\section{SUMMARY}

Deep sedation and a laissez faire attitude occurs in cats when Innovar is placed into the posterior hypothalamus, the centro-median thalamic nucleus and the ventropostero-lateral thalamic nucleus through precise stereotaxically implanted recording cannulae. This sedation persists in the presence of pin-prick stimulation as observed by the persistence of neocortical deactivation and hippocampal activation or seizures. 
Following the application of Innovar into the mesencephalic reticular and pontine reticular formations, no persistent behavioural or electroencephalographic evidence of sedation was observed in the presence of pin-prick stimulation.

\section{RÉSUMÉ}

Il se produit une sédation profonde et une attitude de "laisser faire" chez les chats lorsqu'on introduit de l'Innovar dans l'hypothalamus postérieur, dans le noyau thalamique centro-médian, et dans le noyau thalamique ventro-postéro-latéral, à l'aide de canules enregistreuses implantées avec précision par une technique stéréotaxique. Cette sédation persiste en présence d'une stimulation par piqure d'épingle comme on l'a observé par la persistance de déactivation néocorticale et d'activation ou attaque de l'hyppocampe.

A la suite d'application d'Innovar dans les formations réticulaires mésencéphaliques et dans les formations réticulaires protubérentielles, on n'a observé aucune évidence de sédation persistante ni dans la conduite générale ni dans l'électroencéphalographie, même après stimulation par piqure d'épingle.

\section{REFERENCES}

1. Yezxosky, J.; Katz, R.; \& Dietrich, E. V. A Study of Some of the Pharmacologic Actions of Droperidol. Toxicol. Appl. Pharmacol., 6: 37 (1964).

2. Gardocki, J. F. \& Yelnosky, J. A Study of Some of the Pharmacologic Actions of Fentanyl Citrate. Toxicol. Appl. Pharmacol., 6: 48 (1964).

3. Walker, R. \& MCIntyre, J. W. Clinical Experience with a Combination of Fentanyl and Droperidol. Canad. Anaesth. Soc. J., 12: 361 (1965).

4. HaAse, H. J. \& Jansen, P. A. J. The Action of Neuroleptic Drugs; A Psychiatric and Pharmacological Investigation. Holland Publishing Company (1965).

5. Nilson, E. Origin, Rationale and Practical Use of Neurolept-Analgesia. Irish J. M. Sc., 6: 407 (1963).

6. Mandestem, J. P. An Inquiry into The Use of Innovar for Pediatric Medication. Anesth. \& Analg., 49: 746 (1970).

7. Moruzzi, G. \& Magoun, H. W. Brain Stem Reticular Formation and Activation of the EeG. EEG clin. Neurophysiol., $1: 455$ (1949).

8. Grllhonn, E. Physiological Foundations of Neurology and Psychiatry. Minneapolis, Minn.: University of Minnesota Press (1953).

9. Jouvet, H.; Michel, F.; \& Counjon, J. Sur un staded'activate electrique cerebrale rapide au cours du sonımeil physiologique. C. R. Soc. Biol. (Pris), 153: 1024 (1959).

10. Jenkins, L. C.; Ling, G. M.; Foulks, J. G.; \& Penrose, G. S. Experimental Central Nervons System Studies Related to Anaesthesia: Clinical Implications: r. Anaesthesia and the Brain Stem Reticular Formation. II. Effect of Reduced Sensory Inflow on Anaesthetic Requirements. Canad. Anaesth. Soc. J. 10:634 (1963).

11. Yamaguchi, N.; Ling, G. M.; \& MarczYnski, T. J. Recruiting Responses Observed during Wakefulness and Sleep in Unanaesthetized Chronic Cats. EEG. Clin. Neurophysiol., 17: 246 (1964).

12. Munroe, J. P.; Jenkins, L. C.; \& Ling, G. M. Experimental Central Nervous System Studies Related to Anaesthesia: Clinical Implications. IIr. Effect of Muscle Relaxants on Sensory Inflow. Canad. Anaesth. Soc. J., 13: 109 (1966).

13. Green, J. D. \& Arduini, A. A. Hippocampal Electrical Activity in Arousal. J. Neurophysiol., 17: 533 (1954).

14. Dement, W. \& Kleitman, N. Cyclic Variation in eEg during Sleep and Their Relation to Eye Movements, Body Motility and Dreaming. EEG clin. Neurophysiol., 9: 673 (1957).

15. Gotor, J. \& IKEDA, H. Effect of 5-Hydroxytamine Injected Locally into the Brain Stem on EEG and ECG in Chickens. Jap. J. vet. Sci., 31: 265 (1969).

16. Leighton, K. M. \& Jenkins, L. C. Experimental Studies of The Central Nervous System Related to Anaesthesia: Iv. Effects of Pentobarbital Placement in Caudate Nucleus. Canad. Anaesth. Soc. J., 17: 112 (1970). 